\title{
Partial Molecular Characterization of Dahlia mosaic virus and Its Detection by PCR
}

\author{
M. Nicolaisen, Department of Plant Protection, Danish Institute of Agricultural Sciences, Flakkebjerg, DK4200 \\ Slagelse, Denmark
}

\begin{abstract}
Nicolaisen, M. 2003. Partial molecular characterization of Dahlia mosaic virus and its detection by PCR. Plant Dis. 87:945-948.

Dahlia mosaic virus (DMV) is the causal agent of one of the most important diseases of Dahlia pinnata. The nucleotide sequence of a 1,195-bp fragment of its genome was amplified and characterized. Based on this sequence, polymerase chain reaction (PCR) assays were developed for detection of DMV. The nucleotide sequence confirmed the classification of DMV as a member of genus Caulimovirus since it was similar to a region covering partly open reading frames (ORFs) IV and V found in caulimoviruses. The two most closely related viruses on the basis of comparison of ORF V fragments were shown to be Figwort mosaic virus and Mirabilis mosaic virus with 66.6 and $68.1 \%$ identity, respectively. Two PCR assays were developed using identical primer pairs: a real-time PCR based on SYBR green chemistry and a conventional PCR. Both methods clearly discriminated DMV-infected and healthy dahlia. The real-time PCR assay detected DMV-infected material that was diluted $10^{5}$-fold in healthy material.
\end{abstract}

Dahlia (Dahlia pinnata) is an important bulb crop worldwide used as garden or potted ornamentals. Dahlias are mainly produced using vegetative propagation. One of the most important pathogens affecting dahlia is Dahlia mosaic virus (DMV). Symptoms caused by DMV can vary considerably according to cultivar, but most often consist of mosaic and veinbanding on infected leafs (1). Shortening of internodes leading to stunted plants is also commonly observed (1). The natural mode of transmission of caulimoviruses is by aphids in a non- or semi-persistent manner. The virus can also be transmitted by sap inoculation, although dahlia has high concentrations of tannins and polyphenol oxidases that may be involved in inactivation of viruses in sap (4). Commercial enzymelinked immunosorbent assay (ELISA) test kits for the detection of DMV are available, but these are not very reliable, at least not in our hands.

DMV has been classified as belonging to the genus Caulimovirus based on morphology of particles and inclusion bodies, serological relations to other virions $(4,5)$, and properties of its nucleic acid $(6,13)$. Caulimoviruses have isometric particles of $50 \mathrm{~nm}$ in diameter which contain a circular double-stranded DNA molecule of approximately $8 \mathrm{kbp}$. The complete genomes of

Corresponding author: M. Nicolaisen

E-mail: mogens.nicolaisen@agrsci.dk

Accepted for publication 21 March 2003.

Publication no. D-2003-0519-03R

(C) 2003 The American Phytopathological Society several definitive members of the caulimovirus group, including Cauliflower mosaic virus (CaMV) (7), Carnation etched ring virus (CERV) (9), Figwort mosaic virus (FMV) (12), Strawberry vein banding virus (SVBV) (11), and Mirabilis mosaic virus (MiMV) (Maiti, GenBank accession number AF454635), have been determined. The genome of caulimoviruses consists of seven open reading frames (ORFs): the products of ORF I and II are believed to be involved in cell-to-cell movement and aphid transmission, respectively. The product of ORF III is a nonsequence-specific DNA-binding protein that is required for systemic infection of plants; ORF IV encodes the viral capsid protein; ORF V encodes a polyprotein that is essential for replication; ORF VI encodes a multifunctional protein with functions determining host range and symptom severity; and no product of ORF VII has been detected in infected plants (8).

The genome of DMV has previously been investigated by restriction enzyme mapping (13); however, nucleotide sequence data have not been reported previously. This study reports the nucleotide sequence of a part of the DMV genome consisting of the $3^{\prime}$ end of ORF IV and the $5^{\prime}$ end of ORF V. A polymerase chain reaction (PCR) assay for rapid and sensitive detection of DMV was developed on the basis of the reported nucleotide sequence.

\section{MATERIALS AND METHODS}

Plant material. Dahlias with symptoms typical of DMV (from two dahlia growers) were obtained from Ton van Schadewijk, Dutch Flowerbulb Inspection Service, The Netherlands, and the presence of DMV was confirmed by ELISA using commercial kits including positive controls. Healthy dahlias were obtained from DanElite, Denmark. Infected and uninfected plants were kept separated in greenhouses.

DNA extraction, PCR amplification, cloning and sequencing of DMV DNA. DNA from dahlia was extracted using the DNeasy Plant Mini Kit (QIAGEN Ltd., Crawley, UK) according to manufacturer's instructions, except that $0.1 \%$ mercaptoethanol was added to the extraction buffer to avoid oxidation of plant sap. PCR for general amplification of caulimovirus DNA was done using the following primers: Caulimo IVdeg (5' CAT TAY GCM AAY GAR TGT CC) and Caulimo Vdeg (5' TGC CAN AAT CCN GAY TTA CAG TC) (Fig. 1). These primers were designed in conserved regions of ORF IV and V, respectively, depicted from comparisons of protein sequences from the following caulimoviruses (GenBank accession numbers given in parentheses): MiMV (AF454635), FMV (X06166), CaMV (V00141), CERV (X04658), and SVBV (X97304). PCR was performed with Promega Taq polymerase (Promega, Madison, WI) according to the manufacturer's instructions with $1 \mu$ l total genomic DNA as template and a final $\mathrm{MgCl}_{2}$ concentration of $1.5 \mathrm{mM}$. Amplification conditions were: $2 \mathrm{~min}$ at $94^{\circ} \mathrm{C}$ and 35 cycles at $94^{\circ} \mathrm{C}$ for $30 \mathrm{~s}, 54^{\circ} \mathrm{C}$ for $30 \mathrm{~s}$, and $72^{\circ} \mathrm{C}$ for $90 \mathrm{~s}$, followed by 1 cycle at $72^{\circ} \mathrm{C}$ for $10 \mathrm{~min}$. The completed PCR was analyzed by electrophoresis in a $1 \%$ agarose gel before an aliquot of the PCR products of the expected size was either cloned into pCR 2.1-TOPO using the TOPO TA Cloning Kit (Invitrogen, Groningen, The Netherlands) following the manufacturer's instructions or directly sequenced. Sequencing was done using standard methods with vector or insert specific primers.

Sequence analysis. Database searches were done using BLASTX (2). Protein sequence alignments were constructed, and identity scores were calculated using ClustalW (14).

PCR using DMV-specific primers. DMV-specific primers were designed using Primer Express software (Applied Biosystems, Foster City, CA), and software conditions were set to place primers in separate ORFs. A real-time PCR assay was optimized using the designed primers (DMV forward 5' CAG GAA GAC TAC ATT CCA ATA GAA GAT C $3^{\prime}$ and DMV reverse 5' GCC TTC TGC TTT GTA GTC 
TCT GAA 3') (Fig. 1). PCR assays including optimization of primer concentrations were performed in $20 \mu \mathrm{l}$ with $1 \mathrm{X}$ SYBR green master mix according to manufacturer's instructions (Applied Biosystems). Amplification conditions were: $50^{\circ} \mathrm{C}$ for 2 min and $95^{\circ} \mathrm{C}$ for $10 \mathrm{~min}$ followed by 40 cycles at $95^{\circ} \mathrm{C}$ for $15 \mathrm{~s}$ and $58^{\circ} \mathrm{C}$ for $1 \mathrm{~min}$. The PCR reaction was performed in an $\mathrm{ABI}$ SDS 7000 sequence detection system, and the increase in fluorescence was monitored after each cycle. To check the integrity of the PCR products, a dissociation curve in the temperature interval 62.5 to $87.5^{\circ} \mathrm{C}$ was generated using the ABI SDS 7000, and a few PCR reactions were further analyzed by electrophoresis in an agarose gel.

The designed primers were also used in a conventional PCR assay: PCR was per- formed in a total volume of $25 \mu$ containing $10 \mathrm{mM}$ Tris, $\mathrm{pH} 9.0,50 \mathrm{mM} \mathrm{KCl}, 1.5$ $\mathrm{mM} \mathrm{MgCl}_{2}, 0.1 \%$ Triton X-100, $0.2 \mathrm{mM}$ of each dNTP, $1 \mu \mathrm{M}$ each primer, and 1 unit of Taq DNA polymerase (Promega) on a GeneAmp PCR System 9700 (Applied Biosystems). The cycling conditions were: $95^{\circ} \mathrm{C}$ for $2 \mathrm{~min}$ followed by 35 cycles of $15 \mathrm{~s}$ at $95^{\circ} \mathrm{C}, 30 \mathrm{~s}$ at $58^{\circ} \mathrm{C}$, and $30 \mathrm{~s}$ at $72^{\circ} \mathrm{C}$. At the end, reactions were held at $72^{\circ} \mathrm{C}$ for $10 \mathrm{~min}$. The completed PCR was analyzed by electrophoresis in a $1.5 \%$ agarose gel stained with ethidium bromide.

\section{RESULTS}

Cloning of DMV DNA and sequence analysis. A PCR product of 1,195 bp was generated with DNA from dahlia leaves infected with DMV as template using the primers Caulimo IVdeg and Vdeg in a PCR amplification. The resulting PCR product was both directly sequenced and cloned before its nucleotide sequence was determined for two clones (Fig. 1). The DMV sequence was deposited in GenBank with accession number AJ515906. The sequence data revealed 2 positions with sequence ambiguities both in cloned PCR products and in the directly sequenced PCR products. When the sequence was compared against GenBank using BLASTX, highly significant matches were observed with predicted proteins from caulimovirus ORF IV and V, such as those from FMV, MiMV, and CaMV, suggesting homology. Two partial ORFs (53 amino acids [aa] and 336 aa) were identified in

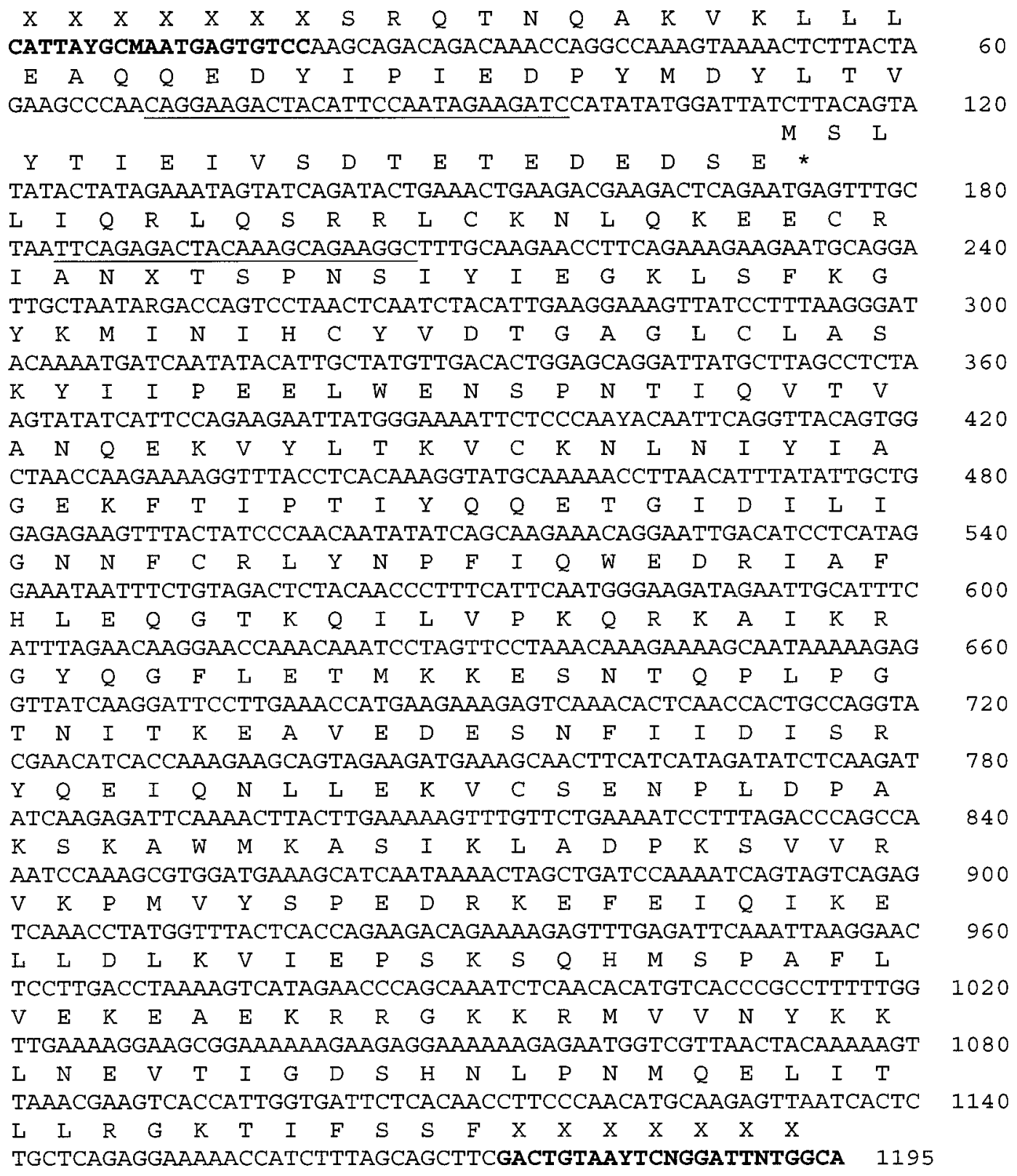

Fig. 1. Nucleotide sequence of the polymerase chain reaction-amplified DNA fragment of Dahlia mosaic virus (DMV). The predicted amino acid sequences are given above the nucleotide sequence. Sequences in bold correspond to the Caulimo IVdeg and Vdeg primers. The DMV forward and reverse primers are underlined. The amino acids corresponding to the sequences including the degenerate primers are shown as $\mathrm{X}=$ any amino acid. 
the sequence homologous to the C-terminal part of the capsid protein of caulimoviruses (ORF IV) and to the N-terminal of the polyprotein of caulimoviruses (ORF V) including an aspartic proteinase (15), respectively. When the $\mathrm{N}$-terminal protein sequence of ORF $\mathrm{V}$ of DMV was compared with ORF $\mathrm{V}$ of other definitive members of the caulimovirus group, MiMV and FMV were the most closely related, with identities of 68.1 and $66.6 \%$, respectively. CERV, CaMV, and SVBV had $56.8,56.7$, and $44.5 \%$ identity to DMV, respectively. This search also revealed matches of less significance to plant genomic sequences (data not shown). The 53 aa C-terminal of the capsid protein showed lower identity to other caulimovirus capsid proteins, with an identity of approximately $40 \%$ to both FMV and MiMV.

PCR detection. A pair of primers for detection of DMV was designed. As some identity between ORF $\mathrm{V}$ and plant genomic DNA was found in homology searches, the two primers were designed in each of the ORFs IV and V to minimize the risk of amplification of plant DNA. A real-time PCR assay based on SYBR green chemistry was developed. The optimal primer concentration in the assay was optimized for low $\mathrm{Ct}$ (first cycle number at which
PCR products are detectable), high deltaRn (amount of PCR products), and no formation of primer-dimer or other unspecific PCR products, and found to be $100 \mathrm{nM}$ for both primers. The optimized PCR assay was tested on DMV-infected and healthy dahlia, and distinguished healthy and infected plants efficiently (Fig. 2). A dissociation curve and agarose gel electrophoresis of the PCR products indicated that only the specific PCR product was generated in detectable amounts (data not shown). Using a 10-fold dilution series of total DNA from DMV-infected leaves in DNA from healthy leaves, it was possible to distinguish a $10^{5}$-fold dilution of infected material from healthy samples in this PCR assay (Fig. 2). To test for nonspecific amplification of DNA from healthy plants, 22 healthy dahlia nuclear stock plants were tested together with DMV-infected plants. None of these 22 plant samples produced a significant signal in the real-time PCR assay, whereas infected plants generated highly significant signals with a $\mathrm{Ct}$ between 17 and 19.

As an alternative to real-time PCR, the primers were also used for detection of DMV in a conventional PCR assay visualized using agarose gel electrophoresis. This assay distinguished DMV-infected and healthy dahlia effectively, as a 138-bp PCR product was generated only when DNA from DMV-infected material was used as template. The bands in lanes 2 and 3 are probably unincorporated nucleotides (Fig. 3).

\section{DISCUSSION}

The partial nucleotide sequence of DMV confirmed the classification of DMV as a member of the genus Caulimovirus. The results of sequence comparisons suggest that DMV is most closely related to FMV and MiMV and more distantly related to the other caulimoviruses CaMV, CERV, and SVBV. In contrast to this, previous studies showed that DMV, CERV, and CaMV were closely related in serological tests (3), whereas MiMV failed to react with DMV antiserum (5). The two identified ORFs showed homology to the corresponding ORFs IV and V from other caulimoviruses: the 53-aa ORF showed homology to the acidic C-terminal of the caulimovirus capsid protein precursor (10); the deduced 336-aa ORF showed homology to the aspartic proteinase located in the $\mathrm{N}$-terminal part of the polyprotein encoded by CaMV ORF V. This proteinase has been shown to be released from the polyprotein by self-cleavage (15).

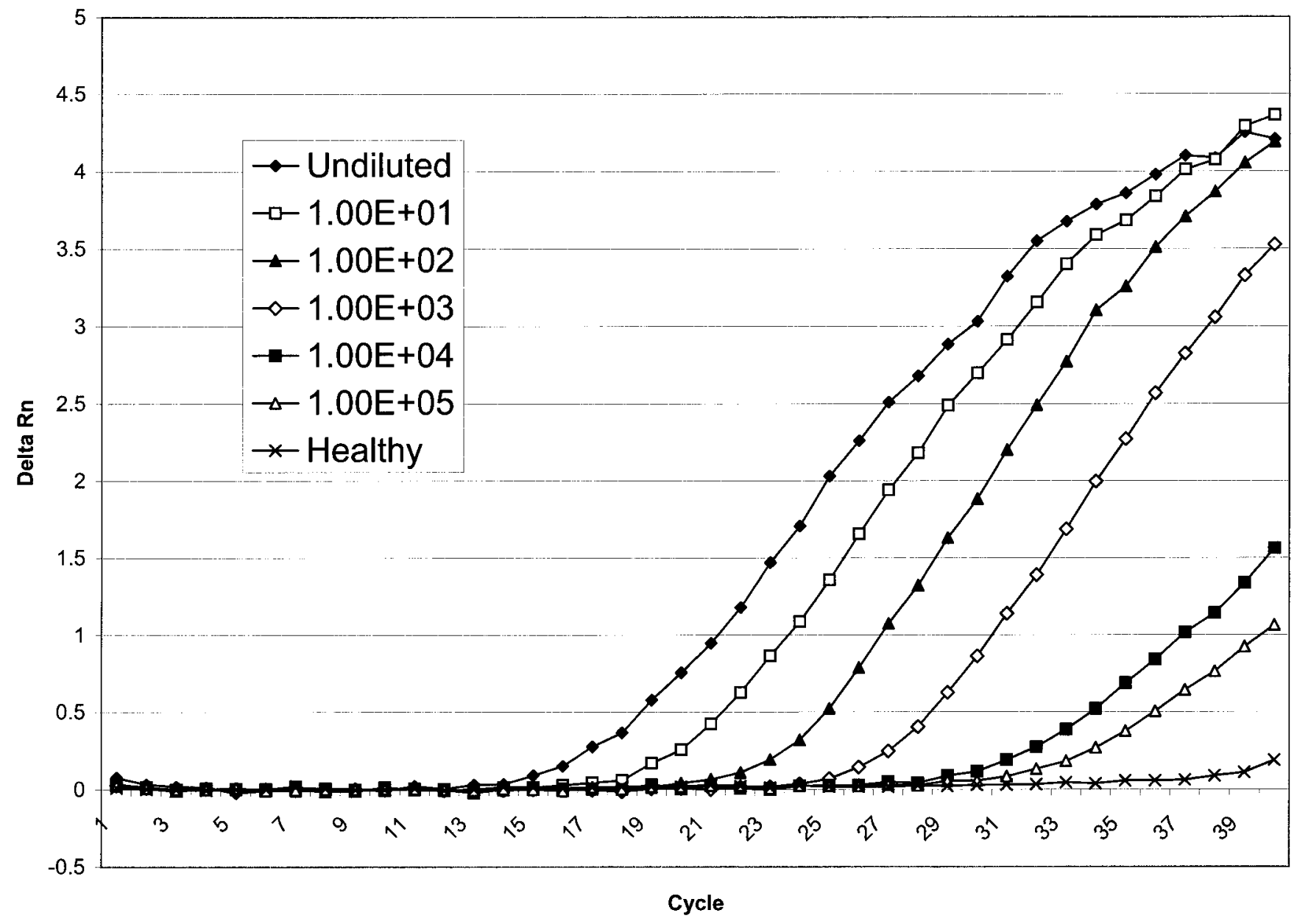

Fig. 2. Amplification plot showing the amplification of Dahlia mosaic virus nucleic acid in a 10-fold dilution series. Normalized fluorescence (Delta Rn) is plotted against polymerase chain reaction cycle number. 


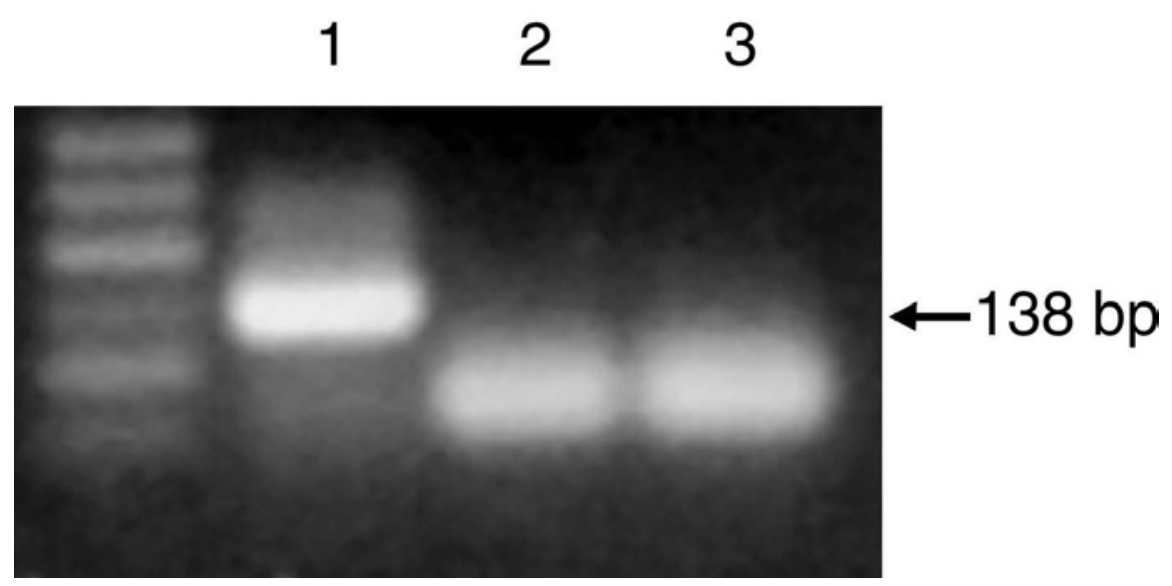

Fig. 3. Agarose gel electrophoresis of polymerase chain reaction (PCR) products generated from DNA extracts from Dahlia mosaic virus-infected Dahlia (lane 1) and healthy Dahlia (lanes 2 and 3). The PCR product of $138 \mathrm{bp}$ in lane 1 is indicated with an arrow. The lanes are flanked by a 50-bp molecular marker.

A PCR assay was developed for the detection of DMV in dahlia. The DMV forward and reverse primers were designed so that the primer pair was located in two different ORFs, the ORF IV and ORF V, respectively, minimizing the risk of amplification of plant DNA sequences leading to false positives. The PCR assay was able to detect DMV, even in highly diluted samples up to at least $10^{5}$-fold, and it did not give rise to significant signals from a number of healthy dahlias. Unfortunately, only two sources of DMV-infected material were available for testing using this PCR assay, as DMV is, to our knowledge, not available from any culture collections. Whether other strains of DMV exist that will escape detection using this assay is not known, but the primers used in this study were located in relatively conserved regions of the DMV genome. The PCR assay was effective using both SYBR green chemistry and a conventional PCR method.
The optimized PCR protocols provided here allow rapid, reliable, and sensitive means of detecting DMV in dahlias. Currently, DMV can be detected by ELISA or by the expression of symptoms in indicator plants; however these assays are not very sensitive and, in our laboratory, often give rise to false positives or false negatives.

I thank Ton van Schadewijk, Dutch Flowerbulb Inspection Service, The Netherlands, and Kaj Nielsen, Dan-Elite, Denmark, for providing infected and healthy plant material.

\section{LITERATURE CITED}

1. Albouy, J. 1995. Dahlia. Pages 265-273 in: Virus and Virus-like Diseases of Bulb and Flower Crops. G. Loebenstein, R. H. Lawson, and A. A. Brunt, eds. John Wiley \& Sons, Chichester.

2. Altschul, S. F., Gish, W., Miller, W., Myers, E. W., and Lipman, D. J. 1990. Basic local alignment search tool. J. Mol. Biol. 215:403-410.

3. Brunt, A. A. 1966. Partial purification, morphology, and serology of Dahlia mosaic virus.

\section{ACKNOWLEDGMENTS}

Virology 28:778-779.

4. Brunt, A. A. 1971. Some hosts and properties of dahlia mosaic virus. Ann. Appl. Biol. 67:357-368.

5. Brunt, A. A., and Kitajima, E. W. 1973. Intracellular location and some properties of Mirabilis mosaic virus, a new member of the Cauliflower mosaic group of viruses. Phytopathol. Z. 76:265-275.

6. Fujisawa, I., Rubio-Huertos, M., and Matsui, C. 1973. Deoxyribonucleic acid in Dahlia Mosaic Virus. Phytopathology 64:287-290.

7. Gardner, R. C., Howarth, A. J., Hahn, P., Brown-Leudi, M., Shepherd, R. J., and Messing, J. 1981. The complete nucleotide sequence of an infectious clone of cauliflower mosaic virus by M13mp7 shotgun sequencing. Nucleic Acids Res. 9:2871-2888.

8. Haas, M., Bureau, M., Geldreich, A., Yot, P. and Keller, M. 2002. Cauliflower mosaic virus: Still in the news. Mol. Plant Pathol. 3:419-429.

9. Hull, R., Sadler, J., and Longstaff, M. 1986. The sequence of carnation etched ring viral DNA: Comparison with cauliflower mosaic virus and retroviruses. EMBO J. 5:3083-3090.

10. Karsies, A., Hohn, T., and Leclerc, D. 2001. Degradation signals within both terminal domains of the cauliflower mosaic virus capsid protein precursor. Plant J. 27:335-343.

11. Petrzik, K., Benes, V., Mraz, I., Honetslegrova-Franova, J., Ansorge, W., and Spak, J. 1998. Strawberry vein banding virus - Definitive member of the genus Caulimovirus. Virus Genes 16:303-305.

12. Richins, R. D., Scholthof, H. B., and Shepherd, R. J. 1987. Sequence of figwort mosaic virus DNA (caulimovirus group). Nucleic Acids Res. 15:8451-8466.

13. Richins, R. D., and Shepherd, R. J. 1983. Physical maps of the genomes of Dahlia Mosaic Virus and Mirabilis Mosaic Virus - Two members of the caulimovirus group. Virology 124:208-214.

14. Thompson, J. D., Higgins D. G., and Gibson, T. J. 1994. Clustal W: Improving the sensitivity of progressive multiple sequence alignment through sequence weighting, position specific gap penalties and weight matrix choice. Nucleic Acids Res. 22:4673-4680.

15. Torruella, M., Gordon, K., and Hohn, T. 1989. Cauliflower mosaic virus produces an aspartic proteinase to cleave its polyproteins. EMBO J. 8:2819-2825. 